\title{
PENGARUH WUDHU TERHADAP PENINGKATAN KONSENTRASI BELAJAR REMAJA
}

\author{
Eni Hidayati ${ }^{1}$, Fakih Anwar Zarkasyi ${ }^{2}$ \\ ${ }^{1,2}$ Keperawatan Fikkes UNIMUS, eni.hidayati82@gmail.com
}

\begin{abstract}
ABSTRAK
Konsentrasi merupakan memfokuskan pikiran terhadap suatu obyek degan mengosongkan pikiran terhadap semua hal lain yang tidak berhubungan Konsentrasi dalam proses belajar adalah salah satu faktor yang sangat penting untuk megikuti suatu proses pembelajaran agar semua proses dalam pembelajaran bisa tercapai dan berhasil untuk meningkatkan konsentrasi salah satunya bisa menggunakan wudhu. Mengetahui pengaruh wudhu terhadap peningkatan konsentrasi pada remaja. Metode penelitian yang digunakan quasi eksperiment. Populasi yang akan digunakan yaitu siswa-siswi yang berjumlah 256 siswa. Teknik sampling yang digunakan purposive sampling dengan jumlah 66 responden terdiri dari kelompok intervensi sebanyak 33 responden dan kelompok kontrol 33 responden. Hasil uji normalitas Shapiro-Wilk diketahui nilai signifikansi (Sig.) 0,00 > 0,05, maka dapat disimpulkan bahwa nilai residual berdistribusi normal, hasil uji Paired Sampel T Test didapatkan hasil nilai sig (2-tailed) sebesar 0,000 $<0,05$ maka dapat disimpulkan ada pengaruh wudhu terhadap peningkatan konsentrasi belajat pada remaja dan hasil uji Homogenitas nilai signifikasi Based on Mean adalah sebesar 0,925>0,05 sehingga bisa disimpulkan bahwa varian data kelas eksperimen dan kontrol adalah sama atau homogen. Hasil penelitian menunjukan bahwa ada pengaruh wudhu terhadap peningkatan konsentrasi belajar pada remaja di . pada kelompok intervensi mean rank pre intervensi dari angka 5,52 dan setelah intervensi menjadi 8,12. Hasil Uji Paired Sample T Test diketahui bahwa nilai sig (2-tailed) sebesar 0,000 < 0,05 yang artinya ada perbedaan rata-rata tingkat konsentrasi untuk pre test dengan post test pada kelompok intervensi. apat memberikan pengetahuan dan gambaran tingkat daya ingat remaja sekolah dan menjadi sudut pandang dalam membuat kebijakan sebagai strategi coping peningkatan konsentrasi belajar pada remaja.
\end{abstract}

Kata Kunci: Belajar, Konsentrasi, Wudhu

\begin{abstract}
Concentration is focusing the mind on an object by emptying the mind on all other unrelated things. Concentration in the learning process is one of the most important factors to follow a learning process so that all learning processes can be achieved and succeed in increasing concentration one of them can use ablution. Determine the effect of ablution on increasing concentration in adolescents. The research method used was quasi experiment. The population that will be used is students, amounting to 256 students. The sampling technique used was purposive sampling with a total of 66 respondents
\end{abstract}


consisting of an intervention group of 33 respondents and a control group of 33 respondents. Results: Shapiro-Wilk normality test results revealed significance values (Sig.) $0.00>0.05$, it can be concluded that residual values were normally distributed, Paired Sample T Test results obtained sig (2-tailed) values of $0,000<0.05$, it can be concluded that there is the effect of ablution on increasing concentration of degrees in adolescents at and the Homogeneity test results of the Significance Based on Mean value are $0.925>0.05$ so it can be concluded that the variant of experimental and control class data is the same or homogeneous. The results showed that there was an influence of ablution on increasing the concentration of learning in adolescents at . in the intervention group the mean rank pre-intervention was 5.52 and after the intervention it was 8.12. Paired Sample T Test Results found that the sig (2-tailed) value of $0,000<0.05$, which means there are differences in the average concentration level for pre-test and post-test in the intervention group. Can provide knowledge and an overview of school teenagers 'memory levels and be a point of view in making policy as a coping strategy for increasing concentration in adolescents' learning.

\section{Keywords: Learning, Concentration, Ablution.}




\section{LATAR BELAKANG}

Masa remaja merupakan periode perubahan pada pertumbuhan dan perkembangan yang pesat baik secara fisik, psikologis maupun intelektual, pada masa ini menuntut remaja untuk lebih mandiri, perkembangan masa remaja mengantarkan pada kebutuhan yang lebih beragam dengan tingkat kesulitan yang lebih tinggi (Susanto, 2018). Pendidikan dalam era globalisasi dianggap hal yang terpenting dan sebagai suatu kebutuhan bagi setiap individu (Shobah, 2018). Presentase remaja yang menempuh pendidikan pada umur 13-15 tahun sebanyak 95,48 \% (Badan Pusat Statistik, 2018).

Pelajar SMP umumnya berumur 13-15 tahun. Pada masa ini, perkembangan otak anak pada daya ingat sangat bagus, namun belum tentu setiap stimulus yang masuk disimpan dalam ingatan. Hal ini tentunya tergantung pada seberapa besar kemampuan perhatian atau konsentrasi individu terhadap stimulus yang diterima (Baharun, 2018). Konsentrasi memiliki pengaruh yang sangat besar dalam pembelajaran agar kompetensi yang diharapkan bisa tercapai (Aslamia, 2018).

Konsentrasi dalam proses belajar adalah salah satu faktor yang sangat penting untuk megikuti suatu proses pembelajaran agar semua proses dalam pembelajaran bisa tercapai dan berhasil (Novianti, 2019). Faktor-faktor yang mempengaruhi konsentrasi belajar yaitu faktor internal seperti malas atau lemah dalam menerima pelajaran, emosi dan reaksi siswa pada lingkungan. Dan faktor eksternal seperti suara bising, teman yang mengganggu, suhu ruangan, tempat belajar yang ramai, tidak adanya peralatan yang dibutuhkan serta kelelahan aktivitas fisik dan mental (Hasnawati S, 2018).

Cara membangun konsentrasi belajara diantaranya lingkungan belajar harus kondusif, kesiapan siswa dalam belajar,mengetahui cara belajar yang baik, menanamkan motivasi dan minat belajar dengan cara mengembangkan "imajinasi berfikir" dan "aktif bertanya" dan menyediakan waktu untuk refreshing (menyegarkan fikiran) ketika mengalami kejenuhan dalam belajar (Hendra Surya, 2011).

Wudhu termasuk salah satu metode yang sangat mudah untuk relaksasi yang bisa dilakukan setiap hari. Hakikatnya wudhu tidak hanya untuk pembersih diri saja, wudhu juga berpengaruh pada terapi yang luar biasa bagi ketenangan jiwa (Purnamasari dkk, 2018). Selain itu wudhu juga membantu mengesampingkan pikiran-pikiran yang mengurangi emosi, duniawi, memberikan waktu untuk memulai kembali untuk berfikir jernih dan untuk berkonsentrasi terutama untuk pelajar yang dalam proses pembelajaran.

Manfaat wudhu untuk kesehatan fisik, diantaranya mencegah penyakit rongga hidung dan penyakit pernafasan (ISPA), memperlancar aliran darah dan membuat kulit tetap cerah dan bercahaya (Akrom, 2010). Sedangkan manfaat bagi psikis diantaranya mereduksi marah, membantu pikiran berkonsentrasi dan menenangkan jiwa (El-Bantanie, 2010).

\section{METODE PENELITIAN}

Penelitian yang akan dilaksanakan oleh peneliti yaitu penelitian kuantitatif dengan jenis prediktif atau pengaruh dengan tujuan mengetahui faktor-faktor yang mempengaruhi antar variabel (Sujarweni, 2014). Desain penelitian yang akan dilakukan menggunakan quasi eksperimen dengan rancangan two group pre-post 
test design yang menjelaskan suatu hubungan sebab akibat dengan melibatkan dua kelompok subjek yaitu pada kelompok intervensi dan kontrol (Nursalam, 2013).

Populasi pada penelitian yang akan dilakukan adalah siswa kelas 7. Cara pengambilan sampel yang digunakan dalam penelitian ini adalah menggunakan purposive sampling dengan menggunakan rumus Isaac and Michael jumlah sampel menjadi 66 responden. Alat pengumpulan data berupa alat ukur berbentuk tes konsentrasi. Tes konsentrasi yang diberikan menggunakan Tes Concentration Grid Exercise terdiri dari 100 kotak yang memuat angka dari 10 sampai 99 secara acak. Proses berlangsung mulai tanggal 2 minggu. Data dianalisis secara univariat dan bivariat (shapiro wilk dan uji paired sample T test dan uji homogenitas).

\section{HASIL DAN PEMBAHASAN}

Berdasarkan Tabel 1 di atas dapat dilihat dari nilai pada kelompok intervensi sebelum diberikan pelakuan wudhu dengan responden sebanyak 33 orang didapatkan rata-rata nilai tingkat konsentrasi 5,52 setelah diberikan wudhu menjadi 7,67. Dengan standar deviasi dari nilai 2,425 menjadi 2,314. Untuk nilai tingkat konsentrasi terendah dari nilai 2 menjadi 3 dan tertinggi dari nilai 11 menjadi 12 .

Berdasarkan tabel 2 di atas menunjukkan dari 33 responden kelompok intervensi dihasilkan: sebelum perlakuan wudhu terdapat 19 responden $(57,9 \%)$ dalam kategori sangat rendah, 13 responden $(39,4 \%)$ dalam kategori rendah, 1 responden $(3 \%)$ dalam kategori sedang, dan setelah diberi perlakuan wudhu menjadi 3 responden $(9,1 \%)$ dalam kategori sangat rendah, 21 responden $(63,6 \%)$ dalam kategori rendah, 9 responden $(27,3 \%)$ dalam kategori sedang.

Tabel 1

Tingkat Konsentrasi Kelompok Intervensi Pada Remaja Sebelum dan Setelah diberikan Wudhu ( $\mathrm{n}=33)$

\begin{tabular}{|c|c|c|c|c|c|}
\hline & $\mathbf{N}$ & Mean & Minimum & Maximum & Std. Deviation \\
\hline $\begin{array}{l}\text { Sebelum } \\
\text { Wudhu }\end{array}$ & 33 & 5,52 & 2 & 11 & 2,425 \\
\hline SesudahWudhu & 33 & 7,67 & 3 & 12 & 2,314 \\
\hline
\end{tabular}

Tabel 2

Distribusi Frekuensi Responden Berdasarkan Perbedaan Tingkat Konsentrasi Sebelum dan Sesudah Perlakuan Wudhu pada Kelompok Intervensi ( $n=33)$

\begin{tabular}{cccccc}
\hline No & $\begin{array}{c}\text { Kategori Tingat } \\
\text { Konsentrasi }\end{array}$ & \multicolumn{2}{c}{ Pre intervensi } & \multicolumn{2}{c}{ Post Intervensi } \\
\cline { 3 - 6 } & Frequency & Percent & Prequency & Percent \\
\hline 1 & Sangat Rendah & 19 & 57,6 & 3 & 9,1 \\
\hline 2 & Rendah & 13 & 39,4 & 21 & 63,6 \\
\hline 3 & Sedang & 1 & 3,0 & 9 & 27,3 \\
\hline 4 & Bagus & 0 & 0 & 0 & 0 \\
\hline 5 & Sangat Bagus & 0 & 0 & 0 & 0 \\
\hline & Total & 33 & 100 & 33 & 100 \\
\hline
\end{tabular}

Berdasarkan tabel 3 menunjukan bahwa adanya perbedaan tingkat konsentrasi pada remaja pada kelompok intervensi mean rank pre intervensi dari angka 5,52 dan setelah intervensi menjadi 8,12. Sedangkan pada kelompok kontrol mean rank observasi awal sebesar 7,18 dan pada observasi akhir sebesar 
6,94. Hasil Uji Paired Sample T Test diketahui bahwa nilai sig (2-tailed) sebesar $0,000<0,05$ yang artinya ada perbedaan rata-rata tingkat konsentrasi untuk pre test dengan post test pada kelompok intervensi. Dan pada kelompok kontrol tidak ada perbedaan rata-rata tingkat konsentrasi untuk observasi awal dan observasi akhir dengan nilai sig (2-tailed) sebesar 0,714 >0,05. Jadi kesimpulannya Ha diterima, sehingga dapat disimpulkan juga bahwa wudhu dapat meningkatkan konsentrasi belajar pada remaja.

Berdasarkan nilai signifikasi Based on Mean adalah sebesar 0,925 >0,05 sehingga bisa disimpulkan bahwa varian data kelas eksperimen dan kontrol adalah sama atau homogen. Dengan demikian maka salah satu syarat (tidak mutlak) dari uji Independent sample T Test sudah terpenuhi.

Tabel 3

Perbedaan Tingkat Konsentrasi pada Remaja pada Kelompok Intervensi dengan

Kelompok Kontrol $(\mathrm{n}=33)$

\begin{tabular}{lccll}
\hline \multicolumn{1}{c}{ Kelompok } & Mean & $\mathbf{N}$ & Std. deviation & Std. Error Mean \\
Pre Intervensi & 5,52 & 33 & 2,425 & 0,422 \\
\hline Post Itervensi & 8,12 & 33 & 2,382 & 0,415 \\
\hline Pre Kontrol & 7,18 & 33 & 4,104 & 0,714 \\
\hline Post Kontrol & 6,94 & 33 & 2,410 & 0,420 \\
\hline
\end{tabular}

Tabel 4

Uji Homogenitas (Persamaan) Tingkat Konsentrasi pada Remaja pada kelompok Intervensi dan kelompok Kontrol (n66)

\begin{tabular}{|l|c|}
\hline \multicolumn{1}{|c|}{ Hasil } & Sig. \\
\hline Based on Mean & 0,925 \\
\hline Based on Median & 0,823 \\
\hline Based on Median and with adjusted df & 0,823 \\
\hline Based on trimmed mean & 0,896 \\
\hline
\end{tabular}

\section{PEMBAHASAN}

Pada penelitian ini, berdasarkan tingkat konsentrasi pada remaja di , sampel ini berjumlah 66 reponden dan sibagi menjadi 2 kelompok, yaitu kelompok intervensi dan kelompok kontrol. Pada kelompok intervensi sebelum diberikan perlakuan wudhu yang berjumlah 33 responden yang diantaranya terdiri atas 15 responden laki-laki serta 18 responden perempuan. Sebagian responden lebih dominan mempunyai tingkat konsentrasi sangat rendah, hasil pre test pada kelompok intervensi yaitu untuk tingkat konsentrasi sebanyak 19 responden $(57,9 \%)$ dalam kategori sangat rendah, 13 responden $(39,4 \%)$ dalam kategori rendah, 1 responden $(3 \%)$ dalam kategori sedang. Pada kelompok kontrol 33 responden kelompok kontrol terdiri atas 12 orang $(36,4 \%)$ laki-laki, sedangkan 21 orang $(63,6 \%)$ perempuan. Sebagian responden lebih dominan mempunyai tingkat konsentrasi rendah. Pada kelompok kontrol dihasilkan 13 responden $(39,4 \%)$ dalam kategori sangat rendah, 14 responden $(42,4 \%)$ dalam kategori rendah, 4 responden $(12,1 \%)$ dalam kategori sedang.

Konsentrasi dipengaruhi oleh beberapa hal. Seperti Lingkungan belajar harus kondusif, kesiapan siswa dalam belajar, belajar aktif, mengetahui cara belajar yang baik, menanamkan motivasi dan minat belajar dengan cara 
mengembangkan "imajinasi berfikir" dan "aktif bertanya", Menyediakan waktu untuk refreshing (menyegarkan fikiran) ketika mengalami kejenuhan dalam belajar (Hendra Surya, 2011).

Hasil berdasarkan tingkat konsentrasi pada remaja di setelah diberikan wudhu sebagian besar menggunakan konsentrasi rendah, setelah diberi perlakuan wudhu menjadi 3 siswa $(9,1 \%)$ dalam kategori sangat rendah, 21 siswa $(63,6 \%)$ dalam kategori rendah, 9 siswa $(27,3 \%)$ dalam kategori sedang. Berdasarkan hasil Uji Paired Sample T Test kelompok intervensi sebelum dan sesudah diberikan wudhu diperoleh nilai sig (2-tailed) sebesar 0,000 $<0,05$ maka dapat disimpulkan ada perbedaan rata-rata tingkat konsentrasi remaja di untuk pre test kelas dengan post test kelompok intervensi.

Peningkatan tingkat konsentrasi yang telah melaksanakan wudhu dapat terjadi karena adanya perubahan perilaku yang secara sadar dalam menyikapi suatu keadaan yang dialaminya, dalam hal ini keadaan yang dimaksud adalah siswa yang mengalami penurunan konsentrasi dalam belajar. Wudhu termasuk salah satu cara meningkatkan konsentrasi dan menenangkan jiwa. Ketika seseorang berwudhu, diwajibkan mengusap kepala dengan air. Tentunya ini akan menjadikan efek sejuk dikepala kita, sehingga pikiran menjadi tenang. Dengan fikiran tenang, seseorang lebih mampu untuk mengkonsentrasikan fikiran kita. Para ahli syaraf (neurologis) telah membuktikan bahwa air wudhu dapat mendinginkan ujung syaraf jari dan tangan dan kaki sehingga mempengaruhi memaksimalkan konsentrasi seseorang (Lela dkk, 2016). Wudhu dinilai efektif dalam mengatasi kurangnya konsentrasi dalam belajar. Hakikatnya wudhu tidak hanya untuk pembersih diri saja, wudhu juga berpengaruh pada terapi yang luar biasa bagi ketenangan jiwa (Purnamasari dkk, 2018).

Penelitian ini menggunakan Uji Paired Sample T Test diketahui kelompok intervensi diperoleh nilai sig (2-tailed) sebesar $0,000<0,05$ maka dapat disimpulkan ada perbedaan rata-rata tingkat konsentrasi remaja untuk pre test kelas eksperiment dengan post test kelompok intervensi dan pada kelompok kontrol tidak ada perbedaan rata-rata tingkat konsentrasi untuk observasi awal dan observasi akhir dengan nilai sig (2-tailed) sebesar 0,714>0,05. Jadi kesimpulannya Ha diterima, sehingga dapat disimpulkan ada pengaruh wudhu terhadap peningkatkan konsentrasi belajar pada remaja.

\section{KESIMPULAN}

Penelitian ini menunjukkan bahwa tingkat konsentrasi pada kelompok intervensi sebelum diberikan perlakuan wudhu berjumlah 19 responden $(57,6 \%)$ dalam kategori sangat rendah, 13 responden $(39,4 \%)$ dalam kategori rendah dan 1 responden $(3 \%)$ dalam kategori sedang dan setelah diberikan perlakuan wudhu menjadi 3 responden $(9,1 \%)$ dalam kategori sangat rendah, 21 responden $(63,6 \%)$ dalam kategori rendah, 9 responden $(27,3 \%)$ dalam kategori sedang. Hasil penelitian menunjukan bahwa ada pengaruh wudhu terhadap peningkatan konsentrasi belajar pada remaja. pada kelompok intervensi mean rank pre intervensi dari angka 5,52 dan setelah intervensi menjadi 8,12. Hasil Uji Paired Sample $T$ Test diketahui bahwa nilai sig (2-tailed) sebesar 0,000 $<0,05$ yang artinya ada perbedaan rata-rata tingkat konsentrasi untuk pre test dengan post test pada kelompok intervensi. 


\section{DAFTAR PUSTAKA}

Akrom, M. (2010). Terapi Wudhu Sempurna Sholat, Bersihkan Penyakit (Destyan \& Aning, eds.). Yogyakarta: Mutiara Media.

Aslamia, S. (2018). Pengaruh Konsentrasi Belajar Terhadap Hasil Belajar Siswa Pada Mata Pelajaran Fikih Kelas X Madrasah Aliyah Negeri 2 Model Pekanbaru. https://doi.org/10.1017/CBO9781107415324.004

Badan Pusat Statistik. (2018). Prevalensi usia anak sekolah di Indonesia. Retrieved from https://www.bps.go.id/

Baharun, H. (2018). Penguatan Daya Ingat Mahasantri Melalui Mnemonic Learning. Jurnal Pedagogik, 05(02), 180-192. Retrieved from https://ejournal.unuja.ac.id/index.php/pedagogik

El-Bantanie, M. S. (2010). Dahsyatnya Terapi Wudhu (A. Subandi, ed.). Retrieved

from https://books.google.co.id/books?id=AnzR1_II8X8C\&printsec=frontcover\& $\mathrm{dq}=$ wudhu \&hl=id\&sa=X\&ved=0ahUKEwicnpPj6enlAhUQA3IKHcnnAVA Q6AEIKjAA\# $\mathrm{v}=$ onepage $\& \mathrm{q}=$ wudhu $\& \mathrm{f}=$ false

Hasnawati S. (2018). Efektivitas Senam Otak Terhadap Konsentrasi Belajar Siswa Pada Pembelajaran Materi Sistem Saraf Kelas XI MAN 1 Polman. Journal of Chemical Information and Modeling. Retrieved from http://repositori.uinalauddin.ac.id/12268/1/Efektivitas Senam Otak terhadap Konsentrasi Belajar Siswa pada Pembelajaran Materi Sistem Saraf Kelas XI MAN 1 Polman.pdf Hendra Surya. (2011). Strategi Jitu Mencapai Kesuksesan Belajar (1st ed.). Jakarta: PT Elex Media Komputindo.

Lela, \& Lukmawati. (2016). "Ketenangan": Makna Dawamul Wudhu (Studi Fenomenologi Pada Mahasiswa UIN Raden Fatah Palembang). Psikis: Jurnal Psikologi Islami, 1(2), 55-66. Retrieved from http://jurnal.radenfatah.ac.id/index.php/psikis/article/download/568/505/

Novianti, R. (2019). Pengaruh Lingkungan Belajar Terhadap Tingkat Konsentrasi Belajar Siswa Pada Mata Pelajaran Akidah Akhlak Di MAN 2 Palembang. $J$

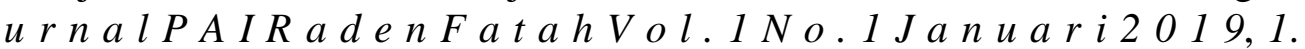
https://doi.org/10.1017/CBO9781107415324.004

Nursalam. (2013). Konsep Penerapan Metode Penelitian Ilmu Keperawatan. Jakarta: Salemba Medika.

Purnamasari, I., \& Fitriani, D. R. (2018). Analisis Praktek Klinik Keperawatan Jiwapada Bpk.S Dengan Intervensi Inovasi Hydro Therapy Wudhu Terhadap Risiko Perilaku Kekerasan Diruang Tiung RSJD. Atma Husada Samarinda. (September). Retrieved from https://dspace.umkt.ac.id//handle/463.2017/882

Shobah, N. L. (2018). Flow Akademik Pada Mahasiswa Diajukan Kepada Universitas Islam Negeri Sunan Ampel Surabaya untuk Memenuhi Salah Satu Persyaratan dalam Menyelesaikan Program Strata Satu ( S1 ) Psikologi ( S . Psi ) Nurul Lailatus Shobah PROGRAM STUDI PSIKOLOGI. Retrieved fromhttp://digilib.uinsby.ac.id/24318/1/NurulLailatusShobah_J01214019.pdf Sujarweni, V. W. (2014). Metodologi Penelitian Keperawatan (1st ed.; D. A, ed.). Yogyakarta: Penerbit Gava Media.

Susanto, A. (2018). Bimbingan dan Konseling di Sekolah Konsep, Teori dan Aplikasinya. Jakarta: Prenadamedia Grup. 